\title{
Ultra-Low Fouling and High Antibody Loading Zwitterionic Hydrogel Coatings for Sensing and Detection in Complex Media
}

\author{
Ying-Nien Chou, ${ }^{\dagger, \downarrow, \S}$ Fang Sun,${ }^{\dagger} \S$ Hsiang-Chieh Hung, ${ }^{\dagger}$ Priyesh Jain, ${ }^{\dagger}$ Andrew \\ Sinclair, ${ }^{\dagger}$ Peng Zhang, ${ }^{\dagger}$ Tao Bai, ${ }^{\dagger}$ Yung Chang, ${ }^{\perp}$ Ten-Chin Wen* ${ }^{*}{ }^{\dagger}$ Qiuming Yu, ${ }^{\dagger}$ \\ Shaoyi Jiang* ${ }^{\dagger}$
}

${ }^{\dagger}$ Department of Chemical Engineering, University of Washington, Seattle, Washington 98195-1750, USA

Department of Chemical Engineering, National Cheng Kung University, Tainan 70101, Taiwan

${ }^{\perp}$ R\&D Center for Membrane Technology and Department of Chemical Engineering, Chung Yuan Christian University, Chung-Li, Taoyuan 320, Taiwan

$\S$ These authors contributed equally to this work

* Corresponding author. Department of Chemical Engineering, University of Washington, Seattle, Washington 98195, USA. Phone: 1-206-616-6509, Fax: 1-206-543-3778. E-mail: sjiang@uw.edu (S. Jiang).

** Corresponding author. Department of Chemical Engineering, National Cheng Kung University, Tainan 70101, Taiwan. Phone: 886-3-265-4122, Fax: 886-3-265-4199.

Email: cwen@ mail.ncku.edu.tw (T.C.Wen) 


\begin{abstract}
For surface-based diagnostic devices to achieve reliable biomarker detection in complex media such as blood, preventing nonspecific protein adsorption and incorporating high loading of biorecognition elements are paramount. In this work, a novel method to produce nonfouling zwitterionic hydrogel coatings was developed to achieve these goals. Poly(carboxybetaine acrylamide) (pCBAA) hydrogel thin films (CBHTFs) prepared with a carboxybetaine diacrylamide crosslinker (CBAAX) were coated on gold and silicon dioxide surfaces via a simple spin coating process. The thickness of CBHTFs could be precisely controlled between 15 and $150 \mathrm{~nm}$ by varying the crosslinker concentration, and the films demonstrated excellent longterm stability. Protein adsorption from undiluted human blood serum onto the CBHTFs was measured with surface plasmon resonance (SPR). Hydrogel thin films greater than $20 \mathrm{~nm}$ exhibited ultra-low fouling $\left(<5 \mathrm{ng} / \mathrm{cm}^{2}\right)$. In addition, the CBHTFs were capable of high antibody functionalization for specific biomarker detection without compromising their nonfouling performance. This strategy provides a facile method to modify SPR biosensor chips with an advanced nonfouling material, and can be potentially expanded to a variety of implantable medical devices and diagnostic biosensors.
\end{abstract}

KEYWORDS: hydrogel coatings; zwitterionic polymers; carboxybetaine; sensing and diagnostics; complex media. 


\section{Introduction}

Avoiding nonspecific protein adsorption is critical in numerous fields. Biosensors, implanted medical devices, drug delivery systems and ship hulls all benefit tremendously from nonfouling surface chemistries [1-4]. Many materials have been reported to reduce protein fouling, but key challenges remain. Although poly(ethylene glycol) (PEG) and its derivatives are the most widely used nonfouling materials, they are susceptible to oxidative damage over longterm use, difficult to directly functionalize with biomolecules for biosensing applications, and have limited nonfouling capabilities in complex, real-world media such as undiluted blood plasma and serum [5,6]. Zwitterionic materials such as phosphorylcholine (PC), sulfobetaine (SB) and carboxybetaine (CB) are attractive alternatives and have seen increasing investigation [7-11]. Poly(carboxybetaine) materials, including poly(carboxybetaine methacrylate) (pCBMA) and poly(carboxybetaine acrylamide) (pCBAA), are particularly interesting. They exhibit ultralow fouling properties (i.e., $<5 \mathrm{ng} / \mathrm{cm}^{2}$ of nonspecific protein binding) in $100 \%$ blood plasma and serum $[12,13]$. In addition, abundant carboxylic acid groups make antibody functionalization to pCB straightforward via amino coupling chemistries [14]. These materials have proven useful for cancer diagnosis in whole blood $[14,15]$.

Typical methods of coating pCB on surfaces can be classified into two categories: "graftfrom" and "graft-to". In the "graft-from" approach, initiators are first immobilized on a substrate and a polymerization method such as atom transfer radical polymerization (ATRP) is used to grow polymer chains from the surface-bound initiators [8]. The "graft-to" method involves direct attachment of zwitterionic polymers - containing adhesive groups such as DOPA or thiols - onto the target surface $[16,17]$. While the "graft-from" technique is an excellent strategy to achieve a high packing density and controlled film thickness, "graft-to" is a more convenient coating process. However, the "graft-from" ATRP often requires oxygen-free conditions while the "graftto" surface-adhesive polymers require extensive coating optimization. In addition, these quasi2D coatings with high surface packing densities have limited space for subsequent protein immobilization [18]. Thus, new facile strategies to achieve nonfouling coatings with high protein loadings are highly desirable.

Hydrogel coatings are simple and convenient to attain, and several studies have examined their usage for protein resistance and biosensor functionalization [19-25]. The aforementioned PEG is regularly used to generate hydrogels for biomedical applications via photo-initiated 
crosslinking. Although PEG hydrogels resist protein adsorption, they fall short of achieving ultra-low protein adsorption from undiluted blood plasma or serum [26-28]. Polysaccharidebased materials such as dextran have also been reported to form hydrogel coatings on biosensors through a number of different methods, but these coatings could not stand with undiluted blood plasma or serum [29, 30]. A zwitterionic hydrogel film containing phosphorylcholine (PC) groups has been investigated for its swelling properties, but its tolerance to complex media has not been reported [31-33]. Fully zwitterionic hydrogels assembled from a CB monomer and a CB-based crosslinker exhibit many unique qualities - they have been demonstrated to resist nonspecific protein adsorption in undiluted whole blood [34], to prevent the foreign-body reaction to implanted materials [35], and to restrain the differentiation of mesenchymal stem cells [36]. In addition, the three-dimensional (3D) structure of the gel matrix provides many sites amenable to ligand immobilization for the specific detection of biomolecules. These virtues suggest that a pCB-based hydrogel coating may be up to the challenge of resisting protein fouling from complex, real-world media and providing abundant functional groups for the subsequent immobilization of molecular bio-recognition elements while maintaining coating stability and simplicity. To the best of our knowledge, a simple hydrogel coating resisting nonspecific protein adsorption from undiluted blood serum has not been reported.

In this work, we develop a nonfouling, wholly zwitterionic coating based on a pCBAA hydrogel thin film (CBHTF). As shown in Scheme 1, a new zwitterionic CB-based diacrylamide crosslinker (CBAAX) was synthesized for this work. The hydrogel thin films were formed by spin-coating a stock solution containing monomer, crosslinker, and photoinitiator onto a hydrophilic, self-assembled monolayer (SAM)-modified gold surface, followed by ultraviolet (UV) light irradiation. The thicknesses of CBHTFs could be controlled by varying the crosslinker concentration, and the coatings displayed great stability. Optimized formulations of CBHTFs demonstrate ultra-low fouling $\left(<5 \mathrm{ng} / \mathrm{cm}^{2}\right)$ from $100 \%$ human blood serum as measured by surface plasmon resonance (SPR), which has not been previously reported for a hydrogel coating. The CBHTF coating also performed well on a $\mathrm{SiO}_{2}$-modified SPR sensor, indicating its capability for general use. CBHTF-coated SPR sensor chips could further be functionalized with antibodies for specific biomarker detection via the simple 1-ethyl-3-(3dimethylaminopropyl)-carbodiimide/N-hydroxysuccinimide (EDC/NHS) coupling chemistry, which benefits from abundant carboxylic acid groups in the $3 \mathrm{D}$ CBHTF matrix. Antibody 
immobilization and biomarker detection levels were also optimized by controlling the crosslinking density.

\section{Experimental Section}

\subsection{Materials}

CBAA monomers were synthesized following a previously published method [37]. Acryloyl chloride, acetonitrile, tert-Butyl bromoacetate, dichloromethane (DCM), 2-Hydroxy-2methylpropiophenone (HMPP), 11-Mercapto-1-undecanol $\left(\mathrm{C}_{11} \mathrm{OH}\right)$, 1-Decanethiol $\left(\mathrm{C}_{11}\right)$, 12Mercaptododecanoic acid $\left(\mathrm{C}_{11} \mathrm{COOH}\right)$ and phosphate-buffered saline (PBS) were purchased from Sigma Aldrich (St. Louis, MO). 2,2'-Diamino-N-methyldiethylamine and N,NDiisopropylethylamine (DIPEA), and trifluoroacetic acid (TFA) were purchased form TCI (Portland, OR). Ethanol was purchased from Decon Labs (King of Prussia, PA). Sodium acetate anhydrous was purchased from Fluka (subsidiary of Sigma Aldrich, St. Louis, MO). EDC and NHS were purchased from Acros Organics (Geel, Belgium). Pooled human serum was purchased from Biochemed Services (Winchester, VA). Human thyroid stimulating hormone (TSH) antibody and antigen were from Thermo Scientific (Waltham, MA). The buffers including 150 $\mathrm{mM}$ phosphate buffered saline (PBS) at $\mathrm{pH} 7.4,10 \mathrm{mM}$ sodium acetate buffer (SA) at $\mathrm{pH} 5,10$ $\mathrm{mM}$ boric acid (BA) with $300 \mathrm{mM} \mathrm{NaCl}$ at $\mathrm{pH}$ 9, $10 \mathrm{mM}$ glycine (GLY) at $\mathrm{pH} 4$ and $10 \mathrm{mM}$ HEPES at $\mathrm{pH} 7.5$ were prepared for biomolecular conjugation and bioassay. The $\mathrm{pH}$ values were adjusted with $\mathrm{HCl}$ or $\mathrm{NaOH}$, and buffers were degassed prior to use. All water used was purified to $18.2 \mathrm{M} \Omega$ with a Millipore water purification system (Billerica, MA).

\subsection{Synthesis of carboxybetaine diacrylamide crosslinker}

A synthesis schematic of the CBAAX is shown in Scheme 2. A solution of acryloyl chloride $(5.3 \mathrm{~mL}, 65.1 \mathrm{mmol})$ in $20 \mathrm{~mL}$ DCM was added dropwise to a solution of 2,2'-Diamino$\mathrm{N}$-methyldiethylamine $(4 \mathrm{~mL}, 31.0 \mathrm{mmol})$ and DIPEA $(11,9 \mathrm{~mL}, 68.3 \mathrm{mmol})$ in $50 \mathrm{~mL} \mathrm{DCM}$ at $0^{\circ} \mathrm{C}$ over a 30 min period. The reaction mixture was allowed to warm to room temperature and stirred for two hours. The reaction was then washed with $(2 \times 25 \mathrm{~mL})$ water. The aqueous layer was re-extracted with DCM (3 x $75 \mathrm{~mL})$. The combined organic layers were dried using sodium sulfate, filtered, and concentrated in vacuo to leave a residue which was further purified by column chromatography to give compound 2 (5.2 gm) in $75.3 \%$ yield. ${ }^{1} \mathrm{H}$ NMR $\left(300 \mathrm{MHz}, \mathrm{D}_{2} \mathrm{O}\right)$ $\delta 6.02-5.97(\mathrm{~m}, 4 \mathrm{H}), 5.56-5.51(\mathrm{~m}, 2 \mathrm{H}), 3.14(\mathrm{t}, J=6.7 \mathrm{~Hz}, 4 \mathrm{H}), 2.37(\mathrm{t}, J=6.7 \mathrm{~Hz}, 4 \mathrm{H}), 2.07$ $(\mathrm{s}, 3 \mathrm{H})$. 
Compound 2 (3.2 gm, $10.5 \mathrm{mmol}$ ) was dissolved in $20 \mathrm{~mL}$ acetonitrile and tertbutylbromoacetate $(4.2 \mathrm{~mL}, 31.6 \mathrm{mmol})$ was added to it. The reaction contents were stirred for 18 hours at $65^{\circ} \mathrm{C}$ until TLC showed complete consumption of the starting material. The reaction mixture was concentrated to dryness in vacuo and further purified by column chromatography to give compound 3 (4.3 gm) in 72.6\% yield. ${ }^{1} \mathrm{H}$ NMR (300 MHz, DMSO- $\left.d_{6}\right) \delta 6.31-6.08(\mathrm{~m}, 4 \mathrm{H})$, $5.67\left(\mathrm{dd}, J_{1}=J_{2}=2.4 \mathrm{~Hz}, 2 \mathrm{H}\right), 4.48(\mathrm{~s}, 2 \mathrm{H}), 3.75-3.54(\mathrm{~m}, 8 \mathrm{H}), 3.29(\mathrm{~s}, 3 \mathrm{H}), 1.45(\mathrm{~s}, 9 \mathrm{H})$.

Compound 3 (2.0 gm, $4.7 \mathrm{mmol}$ ) was dissolved in $15 \mathrm{~mL}$ DCM and $15 \mathrm{~mL}$ TFA was added. The reaction contents were stirred overnight at room temperature. After complete hydrolysis, the reaction mixture was concentrated in vacuo and co-evaporated with DCM (3 x 15 $\mathrm{mL}$ ). The resulting residual mixture was further dissolved in $15 \mathrm{~mL}$ methanol and $4 \mathrm{mg}$ IRN-78 resin was added to it for complete neutralization. The residue was dissolved in water and lyophilized to give compound 4 in $84.1 \%$ yield. ${ }^{1} \mathrm{H}$ NMR (300 MHz, DMSO- $\left.d_{6}\right) \delta 6.31-6.05$ (m, 4H), $5.63\left(\mathrm{dd}, J_{1}=J_{2}=2.4 \mathrm{~Hz}, 2 \mathrm{H}\right), 3.70(\mathrm{~s}, 2 \mathrm{H}), 3.69-3.50(\mathrm{~m}, 8 \mathrm{H}), 3.21(\mathrm{~s}, 3 \mathrm{H})$.

\subsection{Preparation of CBAA hydrogel solution and coating on SPR sensor chips}

Monomer solutions were prepared in DI water, at a concentration of $9 \%$ by weight. The crosslinker CBAAX was added to these solutions in quantities ranging from 0.5 to $20 \%$ (molar percent of monomer). A $2.5 \%$ (molar percent of monomer) solution of photoinitiator HMPP was then added, and complete solutions were sonicated before spin-coating. The SPR sensor chips were produced by coating a glass slide with a $2 \mathrm{~nm}$ titanium film followed by a $50 \mathrm{~nm}$ gold film using an electron beam evaporator. The gold SPR chips were cleaned and modified with different SAMs by soaking the chips in ethanol solutions containing specified thiols $(1 \mathrm{mM})$ overnight. The chips were then rinsed with DI water and ethanol and dried in a stream of filtered air. The prepared monomer solutions were spin-coated on the cleaned chips at $3000 \mathrm{rpm}$ for $50 \mathrm{~s}$. The spin-coated film was dried with filtered air and the chips were exposed to UV light (6 W; $302 \mathrm{~nm}$ with $280 \mathrm{~nm}$ cutoff filter) for $120 \mathrm{~min}$ to commence polymerization. After UV crosslinking, the hydrogel-coated substrates were immersed in PBS solution for 3 days to allow the hydrogel films to fully swell and remove unreacted reagents. The same CBHTF coating process was conducted on the $\mathrm{SiO}_{2}$-modified $\mathrm{SPR}$ chips. Before spin-coating, the $\mathrm{SiO}_{2}$ surface was washed by immersion in piranha solution for 15 mins followed by ammonium hydroxide solution for 15 mins to generate hydroxyl groups. The chips were then washed with DI water and dried with filtered air. The CBHTF was directly coated on the $\mathrm{SiO}_{2}$ surface without $\mathrm{SAM}$ modification. 


\subsection{Film thickness and film stability analysis}

The thickness of CBHTFs were determined using an ellipsometer, (Model alpha-SE, J.A. Woollam, Lincoln, NE) using a 380-900 nm wavelength range at an incidence angle of $70^{\circ}$. The results were fitted to a Cauchy model. Four locations on each sample were analyzed to ensure uniformity of the hydrogel films. The stability of CBHTFs was studied by monitoring changes in thickness after immersion in PBS solution and shaking for $12 \mathrm{hrs,} 24 \mathrm{hrs}, 3$ days and 30 days. Before each thickness measurement, CBHTF-modified chips were rinsed with DI water and dried with filtered air. All the thicknesses were measured under dry condition unless otherwise specified.

\subsection{Nonspecific protein adsorption, antibody immobilization, and antigen detection}

Nonspecific protein adsorption, antibody immobilization, and antigen detection were monitored using a custom-built four-channel SPR sensor as described previously [38]. To measure protein adsorption, undiluted human serum was injected (10 min, $40 \mu \mathrm{L} / \mathrm{min}$ ) and the wavelength shift between PBS baselines was converted to a surface coverage. Anti-TSH was immobilized by first injecting $10 \mathrm{mM} \mathrm{SA}$ (pH 5), followed by EDC/NHS (0.2 M/0.05 M in water) for $7 \mathrm{~min}$ at $30 \mu \mathrm{L} / \mathrm{min}$. Then, anti-TSH (50 $\mu \mathrm{g} / \mathrm{mL}$ in $10 \mathrm{mM}$ HEPES $\mathrm{pH} 7.5)$ was injected (20 min, $20 \mu \mathrm{L} / \mathrm{min}$ ) followed by deactivation with $10 \mathrm{mM} \mathrm{BA}(\mathrm{pH}$ 9) for $10 \mathrm{~min}$, then $10 \mathrm{mM}$ GLY (pH 4) and SA for $10 \mathrm{~min}$, all at $30 \mu \mathrm{L} / \mathrm{min}$. Immobilization was calculated as the difference between SA baselines before Anti-TSH injection and after deactivation. TSH antigen binding was then monitored by first injecting PBS and then antigen $(1 \mu \mathrm{g} / \mathrm{mL}$ in PBS at $40 \mu \mathrm{L} / \mathrm{min})$ following by PBS.

\subsection{Statistical methods}

Statistical analysis was performed using Excel. Mean values with standard deviation are reported and all experiments were performed in triplicate. The error bars correspond to the standard deviation

\section{Results and Discussion}

\subsection{Synthesis of CBAAX and selection of SAM modification on gold chips}

Crosslinker selection plays an important role in the nonfouling performance of zwitterionic hydrogels [39]. Zwitterionic materials repel nonspecific protein adsorption through strong binding to water via electrostatically induced hydration. However, traditional crosslinkers such as widely-used N,N'-methylenebis(acrylamide) (MBAA) are only moderately water soluble 
(not more than 10\%). They can degrade the nonfouling performance and mechanical strength of the hydrogel system. To overcome this problem, we have synthesized a CBAAX (Scheme 2) for improved solubility, homogeneity, mechanical properties and compatibility with CBAA monomer to form CBAA-based zwitterionic hydrogel coatings.

CBHTF coatings were deposited by spin-coating aqueous hydrogel solutions onto gold chips, followed by photoinitiated polymerization. Notably, we found CBHTF uniformity to be related to the hydrophilicity of a chip surface. Grains and particles were observed in the CBHTF after initial coating on a cleaned bare gold SPR chip. Therefore, further chips were modified with one of several SAMs, including $\mathrm{C}_{11} \mathrm{COOH}, \mathrm{C}_{11} \mathrm{OH}$, and $\mathrm{C}_{11}$, to alter surface hydrophilicity and form a smoother film. CBHTFs could be successfully coated on $\mathrm{C}_{11} \mathrm{COOH}$ and $\mathrm{C}_{11} \mathrm{OH} \mathrm{SAM}$ modified gold chips with relatively good uniformity, while they could not be formed on the $\mathrm{C}_{11}$ SAM-modified chip used as a negative control. Table 1 shows the water surface contact angles of different SAM-modified gold chips for their hydrophilicities. The hydrophobic $\mathrm{C}_{11} \mathrm{SAM}-$ modified substrate presented a $78.3^{\circ}$ contact angle, and strongly repelled the attachment of the aqueous hydrogel solution as expected. The carboxyl tail groups present in the $\mathrm{C}_{11} \mathrm{COOH} \mathrm{SAM}$ resulted in a very low contact angle $\left(\sim 5^{\circ}\right)$, even compared with that of the $\mathrm{C}_{11} \mathrm{OH}$ SAM $\left(\sim 16^{\circ}\right)$. On this $\mathrm{C}_{11} \mathrm{COOH} \mathrm{SAM}$, the CBHTF demonstrated the best uniformity, greatest film thickness and best nonfouling performance. We hypothesize that the fouling resistance of CBHTFs is highly dependent on their surface uniformity, and thus hydrophilic pre-modification of gold chips is necessary for optimal performance. Due to the excellent uniformity of films grown on $\mathrm{C}_{11} \mathrm{COOH}$ SAM-modified chips, we selected this SAM for subsequent experiments to optimize nonfouling and test antibody immobilization.

\subsection{Control of CBHTF thickness and stability test}

The thickness of CBHTFs could be precisely controlled by varying the CBAAX concentration in the stock hydrogel solution. The CBAA monomer concentration was fixed at 9 wt $\%$, and the CBAAX crosslinker was added in ratios from 0 to $20 \mathrm{~mol} \%$ of the CBAA monomer. As shown in Figure 1a, CBHTF thickness increases with an increased crosslinker ratio because of enhanced accumulation of the 3D polymer network. The film thickness in the absence of crosslinker was only $12 \mathrm{~nm}$. In the presence of CBAAX, well-controlled film thicknesses ranging from $\sim 15$ to $\sim 40 \mathrm{~nm}$ could be attained with CBAAX ratios ranging from $0.5 \%$ to $6 \%$, and $\sim 90$ to $\sim 150 \mathrm{~nm}$ thicker films were achieved with higher CBAAX ratios between 10 and 
20\%. Film thicknesses showed higher variations when 20\% CBAAX was used, as the reaction was more difficult to control under this high crosslinker ratio. These two film thickness regions are both desirable for different coating applications.

Figure 1b shows the stability of CBHTFs immersed in PBS for different periods of time. The thickness of CBHTFs containing 20\% CBAAX only decreased slightly after immersion for 30 days, from $145 \mathrm{~nm}$ to $142 \mathrm{~nm}$. Meanwhile, CBHTFs formulated with 3\% and 6\% CBAAX showed even better stability, with no obvious change in film thickness. However, the thickness of the CBAA polymer brush film grafted without CBAAX crosslinker decreased from $12 \mathrm{~nm}$ to 1 nm over one month. These results emphasize how important crosslinker selection is to achieve stable films. With CBAAX incorporation, robust and well-controlled CBHTF coatings were achieved using this simple coating method.

\subsection{Protein resistance test in human blood serum}

To challenge CBHTFs with complex media, we used an SPR sensor to measure protein adsorption from undiluted human blood serum onto CBHTFs of varying thicknesses coated on $\mathrm{C}_{11} \mathrm{COOH}$-modified gold chips. Figure 2 shows this protein adsorption from $100 \%$ serum as a function of CBHTF thickness. High fouling $\left(\sim 40-70 \mathrm{ng} / \mathrm{cm}^{2}\right)$ was seen at a CBHTF thickness of less than $20 \mathrm{~nm}$. However, when the CBHTF thickness was over $25 \mathrm{~nm}$, protein adsorption dropped to an ultra-low fouling level $\left(<10 \mathrm{ng} / \mathrm{cm}^{2}\right)$. The lowest fouling observed was less than 5 $\mathrm{ng} / \mathrm{cm}^{2}$ at a film thickness of $29.7 \mathrm{~nm}$. The maximum film thickness tested was around $45 \mathrm{~nm}$ since the SPR detection sensitivity drops exponentially when away from the surface. The higher level of protein adsorption seen onto 45-nm-thick CBHTFs was attributed to a reduced film uniformity compared with those of lower thicknesses. For pCB brush coatings, a high packing density of zwitterionic moieties is the key to achieving strong hydration and effective nonfouling performance. For CBHTFs, the crosslinking density plays an important role in surface nonfouling properties. Utilizing higher concentrations of CBAAX $(>2 \%)$ allowed us to increase both the film thickness and the degree of crosslinking in a controlled fashion. To test CBHTF performance on a different hydrophilic surface other than COOH SAM, we modified chips with $\mathrm{SiO}_{2}$ before hydrogel coating and serum challenge. Figure 3 shows a typical SPR sensorgram of protein adsorption from undiluted blood serum on these $\mathrm{SiO}_{2}$-modifed chips coated with a 27.2 nm-thick CBHTF. Less than $5 \mathrm{ng} / \mathrm{cm}^{2}$ of protein adsorption was seen for these chips as well, validating the broad applicability of this coating method. For both types of modified chips, 
optimizing the crosslinking density is a key to achieving ultra-low fouling.

\subsection{Surface functionalization and detection}

It has been demonstrated previously that zwitterionic pCB-based coatings possess abundant functionalizable groups that enable antibody immobilization via NHS/EDC aminocoupling chemistries, and that these coated surfaces can maintain an ultra-low fouling background before and after antibody functionalization [27]. However, these pCB coatings are typically grafted via ATRP, and are quasi-two-dimensional (2D) films intrinsically limited to a maximum ligand immobilization capacity of a monomer $\left(\sim 250 \mathrm{ng} / \mathrm{cm}^{2}\right)$. In contrast, the CBHTFs developed in this work comprise a 3D matrix with CB moieties on each monomer and crosslinker unit, enhancing the functionalization capacity well beyond that of $2 \mathrm{D}$ films.

To study the antibody immobilization capacity of CBHTFs, we functionalized the films with antibodies against human thyroid stimulating hormone (anti-TSH). Antigen binding and nonspecific protein from undiluted human serum were investigated using SPR. Figure 4 shows a typical SPR sensorgram of the overall process, i.e., surface activation, antibody immobilization, surface deactivation and antigen detection as conducted on a CBHTF with $4 \%$ CBAAX content as described in the experimental section. Using SPR, we systematically investigated the influence of crosslinking density (i.e., the CBAAX ratio) on antibody loading capacity and antigen detection. As shown in Figure 5, the optimal antibody loading was around $693 \mathrm{ng} / \mathrm{cm}^{2}$ at

a CBHTF thickness of $\sim 28 \mathrm{~nm}$ containing 3\% CBAAX, a threefold higher loading capacity than that of $2 \mathrm{D}$ pCB films previously reported [18]. We also measured the wet thickness of the optimal CBHTF; it had swelled from $\sim 28 \mathrm{~nm}$ to $\sim 63 \mathrm{~nm}$, indicating its 3D structure. Notably, the loading capacity decreased to $411 \mathrm{ng} / \mathrm{cm}^{2}$ in a thicker $\sim 40 \mathrm{~nm}$ film. The higher crosslinker content rendered the gel network denser, inhibiting the diffusion of antibodies to binding sites. The antigen (i.e., TSH) binding capacity in the optimized $\sim 28 \mathrm{~nm}$ film was $68.5 \mathrm{ng} / \mathrm{cm}^{2}$, corresponding to a calculated bioactivity ratio of 0.71 . We also tested the nonspecific fouling resistance of the optimized CBHTF after antibody immobilization, and found it to remain under $5 \mathrm{ng} / \mathrm{cm}^{2}$ from undiluted serum.

In this work, the most important factor to achieve ultra-low fouling and high antibody loading was the crosslinker ratio. Once the crosslinker ratio was above $2 \%$, the CBHTFs demonstrated good stability and showed relatively low protein adsorption due to the higher crosslinking density. However, the optimized crosslinker ratio for maximum antibody loading 
was in the middle of the range, as higher crosslinker content could make the CBHTF too dense and inhibit antibodies from diffusing in. These results indicate that control over the architecture of zwitterionic hydrogel thin films is the key to their unique capacity for ultra-low nonspecific protein adsorption with high ligand loading.

\section{Conclusions}

In summary, we have developed a facile approach to realize ultra-low fouling and high ligand loading with a highly-crosslinked, purely zwitterionic, carboxybetaine thin film hydrogel (CBHTF) coating platform. The CBHTF on a hydrophilic surface demonstrated long-term stability. By varying the crosslinker content in the spin-coated hydrogel solution, the thickness of CBHTFs could be precisely controlled from 15 150 nm. Optimized CBHTFs exhibited ultra-low nonspecific protein adsorption below $5 \mathrm{ng} / \mathrm{cm}^{2}$, and their 3D architecture allowed antibody loading to reach $693 \mathrm{ng} / \mathrm{cm}^{2}$. This facile coating technique was also demonstrated to be directly applicable to an alternative hydrophilic substrate modified with $\mathrm{SiO}_{2}$, indicating that its potentials for broad diagnostic applications.

\section{Acknowledgments}

This work was supported by the National Science Foundation (CBET 1264470). Y.N.C. and Y.C. and T.C.W. would like to acknowledge the $\mathrm{PhD}$ visiting student program and the projects of the Ministry of Science and Technology (102-2221-E-006-219-MY3, 102-2221-E-033-009-MY3 and 103-2221-E-033-078-MY3) for their financial support. 
Table 1. Selection of hydrophilic SAM modifications on gold SPR chips

\begin{tabular}{llccc}
\hline & & \multicolumn{3}{c}{ SAM on gold chip } \\
\cline { 3 - 5 } & Bare gold & $\mathrm{C}_{11} \mathrm{OH}$ & $\mathrm{C}_{11} \mathrm{COOH}$ & $\mathrm{C}_{11}$ \\
\hline $\begin{array}{c}\text { Contact Angle } \\
\left({ }^{\circ}\right)\end{array}$ & $25.6 \pm 2.2$ & $15.7 \pm 1.3$ & $5.2 \pm 1.9$ & $78.3 \pm 3.6$ \\
$\begin{array}{c}\text { Gel Thickness } \\
(\mathrm{nm})\end{array}$ & $22.3 \pm 3.5$ & $26.1 \pm 2.2$ & $29.7 \pm 1.7$ & $1.2 \pm 0.8$ \\
$\begin{array}{c}\text { Serum Fouling } \\
\left(\mathrm{ng} / \mathrm{cm}^{2}\right)\end{array}$ & $17.8 \pm 4.3$ & $9.4 \pm 3.7$ & $3.5 \pm 1.3$ & - \\
\hline
\end{tabular}




\section{References}

[1] Prime KL, Whitesides GM. Self-Assembled Organic Monolayers - Model systems for studying adsorption of proteins at surfaces. Science 1991;252:1164-7.

[2] Ratner BD, Bryant SJ. Biomaterials: Where we have been and where we are going. Annu Rev Biomed Eng 2004;6:41-75.

[3] Langer R. Perspectives: Drug delivery - Drugs on target. Science 2001;293:58-9.

[4] Shapiro MG, Westmeyer GG, Romero PA, Szablowski JO, Kuster B, Shah A, Otey CR, Langer R, Arnold FH, Jasanoff A. Directed evolution of a magnetic resonance imaging contrast agent for noninvasive imaging of dopamine. Nat Biotechnol 2010;28:264-270.

[5] Li LY, Chen SF, Jiang SY. Protein interactions with oligo(ethylene glycol) (OEG) selfassembled monolayers: OEG stability, surface packing density and protein adsorption. J Biomat Sci-Polym E 2007;18:1415-27.

[6] Ostuni E, Chapman RG, Holmlin RE, Takayama S, Whitesides GM. A survey of structureproperty relationships of surfaces that resist the adsorption of protein. Langmuir 2001;17:560520.

[7] Ishihara K, Ueda T, Nakabayashi N. Preparation of phospholipid polymers and their properties as polymer hydrogel membranes. Polym J 1990;22:355-60.

[8] Jiang SY, Cao ZQ. Ultralow-fouling, functionalizable, and hydrolyzable zwitterionic materials and their derivatives for biological applications. Adv Mater 2010;22:920-32.

[9] Iwasaki Y, Ishihara K. Phosphorylcholine-containing polymers for biomedical applications. Anal Bioanal Chem 2005;381:534-46.

[10] Wu L, Jasinski J, Krishnan S. Carboxybetaine, sulfobetaine, and cationic block copolymer coatings: A comparison of the surface properties and antibiofouling behavior. J Appl Polym Sci 2012;124:2154-70.

[11] Sun F, Ella-Menye JR, Galvan DD, Bai T, Hung HC, Chou YN, Zhang P, Jiang SY, Yu QM. Stealth surface modification of surface-enhanced Raman scattering substrates for sensitive and accurate detection in protein solutions. Acs Nano 2015;9:2668-76.

[12] Ladd J, Zhang Z, Chen S, Hower JC, Jiang S. Zwitterionic polymers exhibiting high resistance to nonspecific protein adsorption from human serum and plasma. Biomacromolecules 2008;9:1357-61.

[13] Yang W, Xue H, Li W, Zhang JL, Jiang SY. Pursuing "zero" protein adsorption of poly(carboxybetaine) from undiluted blood serum and plasma. Langmuir 2009;25:11911-6. [14] Vaisocherova H, Yang W, Zhang Z, Cao ZQ, Cheng G, Piliarik M, Homola J, Jiang SY. Ultralow fouling and functionalizable surface chemistry based on a zwitterionic polymer enabling sensitive and specific protein detection in undiluted blood plasma. Anal Chem 2008;80:7894-901.

[15] von Muhlen MG, Brault ND, Knudsen SM, Jiang SY, Manalis SR. Label-free biomarker sensing in undiluted serum with suspended microchannel resonators. Anal Chem 2010;82:190510.

[16] Li GZ, Cheng G, Xue H, Chen SF, Zhang FB, Jiang SY. Ultra low fouling zwitterionic polymers with a biomimetic adhesive group. Biomaterials 2008;29:4592-7.

[17] Sundaram HS, Han X, Nowinski AK, Brault ND, Li YT, Ella-Menye JR, Amoaka KA, Cook KE, Marek P, Senecal K, Jiang SY. Achieving one-step surface coating of highly hydrophilic poly(carboxybetaine methacrylate) polymers on hydrophobic and hydrophilic surfaces. Adv Mater Interfaces 2014;1.

[18] Huang CJ, Brault ND, Li YT, Yu QM, Jiang SY. Controlled hierarchical architecture in 
surface-initiated zwitterionic polymer brushes with structurally regulated functionalities. Adv Mater 2012;24:1834-7.

[19] Xie LY, Hong F, He CX, Ma CF, Liu JH, Zhang GZ, Wu C. Coatings with a self-generating hydrogel surface for antifouling. Polymer 2011;52:3738-44.

[20] Butruk B, Trzaskowski M, Ciach T. Fabrication of biocompatible hydrogel coatings for implantable medical devices using Fenton-type reaction. Mat Sci Eng C-Mater 2012;32:1601-9. [21] Rao L, Zhou HH, Li T, Li CY, Duan YWY. Polyethylene glycol-containing polyurethane hydrogel coatings for improving the biocompatibility of neural electrodes. Acta Biomater 2012;8:2233-42.

[22] Mateescu A, Wang Y, Dostalek J, Jonas U. Thin hydrogel films for optical biosensor applications. Membranes 2012;2:40-69.

[23] Faxalv L, Ekblad T, Liedberg B, Lindahl TL. Blood compatibility of photografted hydrogel coatings. Acta Biomater 2010;6:2599-608.

[24] Toma M, Jonas U, Mateescu A, Knoll W, Dostalek J. Active Control of SPR by

Thermoresponsive hydrogels for biosensor applications. J Phys Chem C 2013;117:11705-12.

[25] Tokarev I, Minko S. Stimuli-responsive hydrogel thin films. Soft Matter 2009;5:511-24.

[26] Larsson A, Ekblad T, Andersson O, Liedberg B. Photografted poly(ethylene glycol) matrix for affinity interaction studies. Biomacromolecules 2007;8:287-95.

[27] Larsson A, Liedberg B. Poly(ethylene glycol) gradient for biochip development. Langmuir 2007;23:11319-25.

[28] Ekblad T, Bergstroem G, Ederth T, Conlan SL, Mutton R, Clare AS, Wang S, Liu YL, Zhao Q, D'Souza F, Donnelly GT, Willemsen PR, Pettitt ME, Callow ME, Callow JA, Liedberg B. Poly(ethylene glycol)-containing hydrogel surfaces for antifouling applications in marine and freshwater environments. Biomacromolecules 2008;9:2775-83.

[29] Masson JF, Battaglia TM, Davidson MJ, Kim YC, Prakash AMC, Beaudoin S, Booksh KS. Biocompatible polymers for antibody support on gold surfaces. Talanta 2005;67:918-25.

[30] Wang Y, Brunsen A, Jonas U, Dostalek J, Knoll W. Prostate specific antigen biosensor based on long range surface plasmon-enhanced fluorescence spectroscopy and dextran hydrogel binding matrix. Anal Chem 2009;81:9625-32.

[31] Lewis AL, Tolhurst LA, Stratford PW. Analysis of a phosphorylcholine-based polymer coating on a coronary stent pre- and post-implantation. Biomaterials 2002;23:1697-706.

[32] Li Y, Liu CM, Yang JY, Gao YH, Li XS, Que GH, Lu JR. Anti-biofouling properties of amphiphilic phosphorylcholine polymer films. Colloid Surface B 2011;85:125-30.

[33] Tang Y, Lu JR, Lewis AL, Vick TA, Stratford PW. Structural effects on swelling of thin phosphorylcholine polymer films. Macromolecules 2002;35:3955-64.

[34] Yang W, Bai T, Carr LR, Keefe AJ, Xu JJ, Xue H, Irvin CA, Chen SF, Wang J, Jiang SY. The effect of lightly crosslinked poly(carboxybetaine) hydrogel coating on the performance of sensors in whole blood. Biomaterials 2012;33:7945-51.

[35] Zhang L, Cao ZQ, Bai T, Carr L, Ella-Menye JR, Irvin C, Ratner BD, Jiang SY. Zwitterionic hydrogels implanted in mice resist the foreign-body reaction. Nat Biotechnol 2013;31:553-6.

[36] Bai T, Sun F, Zhang L, Sinclair A, Liu SJ, Ella-Menye JR, Zheng Y, Jiang SY. Restraint of the differentiation of mesenchymal stem cells by a nonfouling zwitterionic hydrogel. Angew Chem Int Edit 2014;53:12729-34.

[37] Zhang P, Sun F, Tsao C, Liu SJ, Jain P, Sinclair A, Hung HC, Bai T, Wu K, Jiang SY. Zwitterionic gel encapsulation promotes protein stability, enhances pharmacokinetics, and reduces immunogenicity. P Natl Acad Sci USA 2015;112:12046-51. 
[38] Nowinski AK, Sun F, White AD, Keefe AJ, Jiang SY. Sequence, structure, and function of peptide self-assembled monolayers. J Am Chem Soc 2012;134:6000-5.

[39] Bai T, Liu SJ, Sun F, Sinclair A, Zhang L, Shao Q, Jiang SY. Zwitterionic fusion in hydrogels and spontaneous and time-independent self-healing under physiological conditions.

Biomaterials 2014;35:3926-33. 


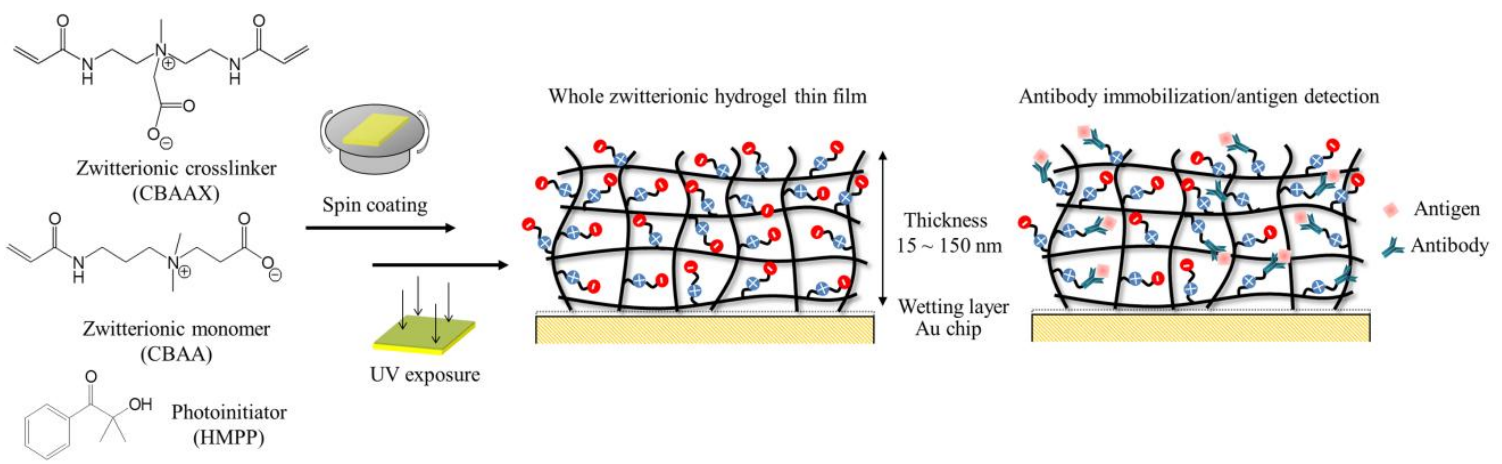

Scheme 1. Overview of the coating process to generate CBHTFs on the surface of SPR chips. 

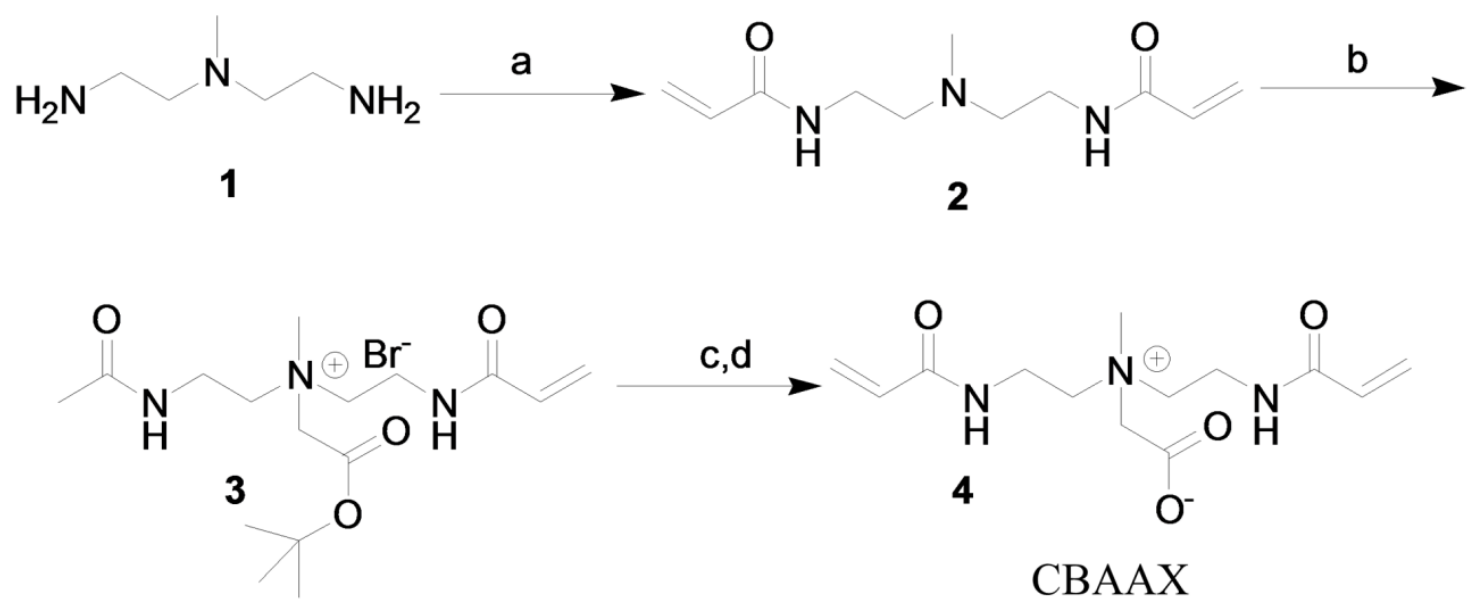

Scheme 2. Chemical synthesis of carboxybetaine diacrylamide (CBAAX). (a) DIEA, Acryloyl chloride, DCM, 75\% (b) $\mathrm{BrCH}_{2} \mathrm{CO}_{2} \mathrm{tBu}, \mathrm{CH}_{3} \mathrm{CN}, 60^{\circ} \mathrm{C}, 73 \%$ (c) TFA:DCM 1:1, (d) $\mathrm{MeOH}$, IRN-78 resin hydrolysis $84 \%$. 

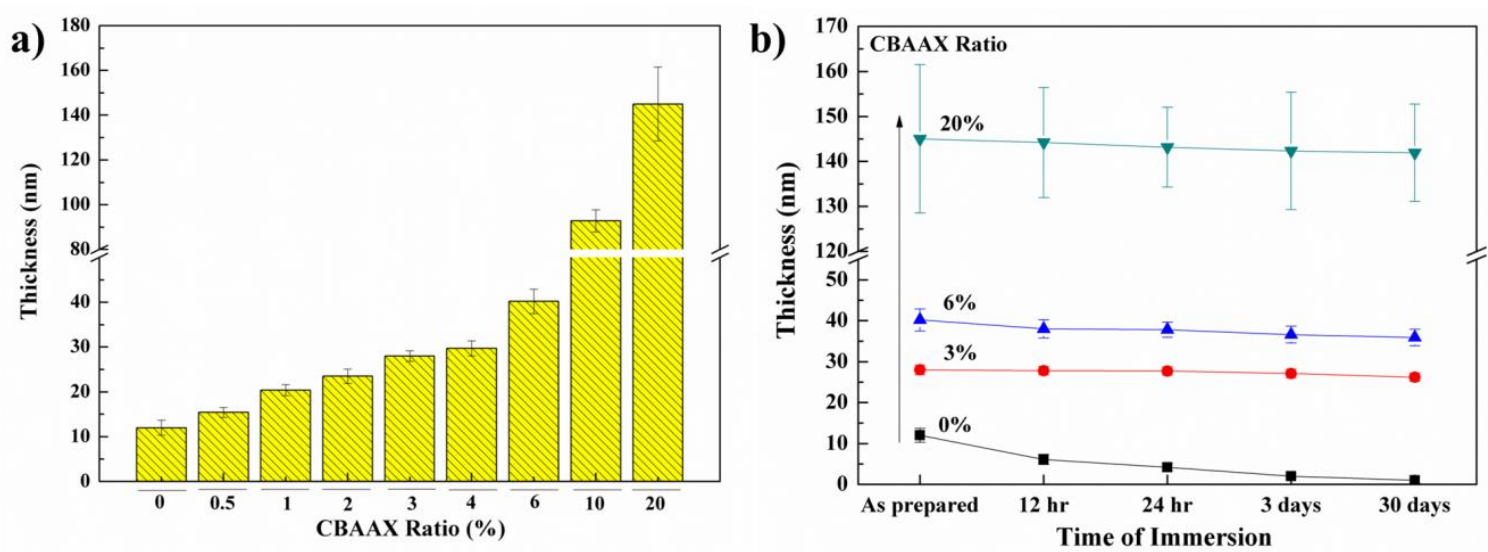

Fig 1. (a) Thickness of CBHTFs as a function of CBAAX ratio, which is presented as a molar percentage of the CBAA monomer; (b) thickness of CBHTFs in a PBS solution as a function of immersion time over 30 days. The error bars correspond to the standard deviation of three replicates. 


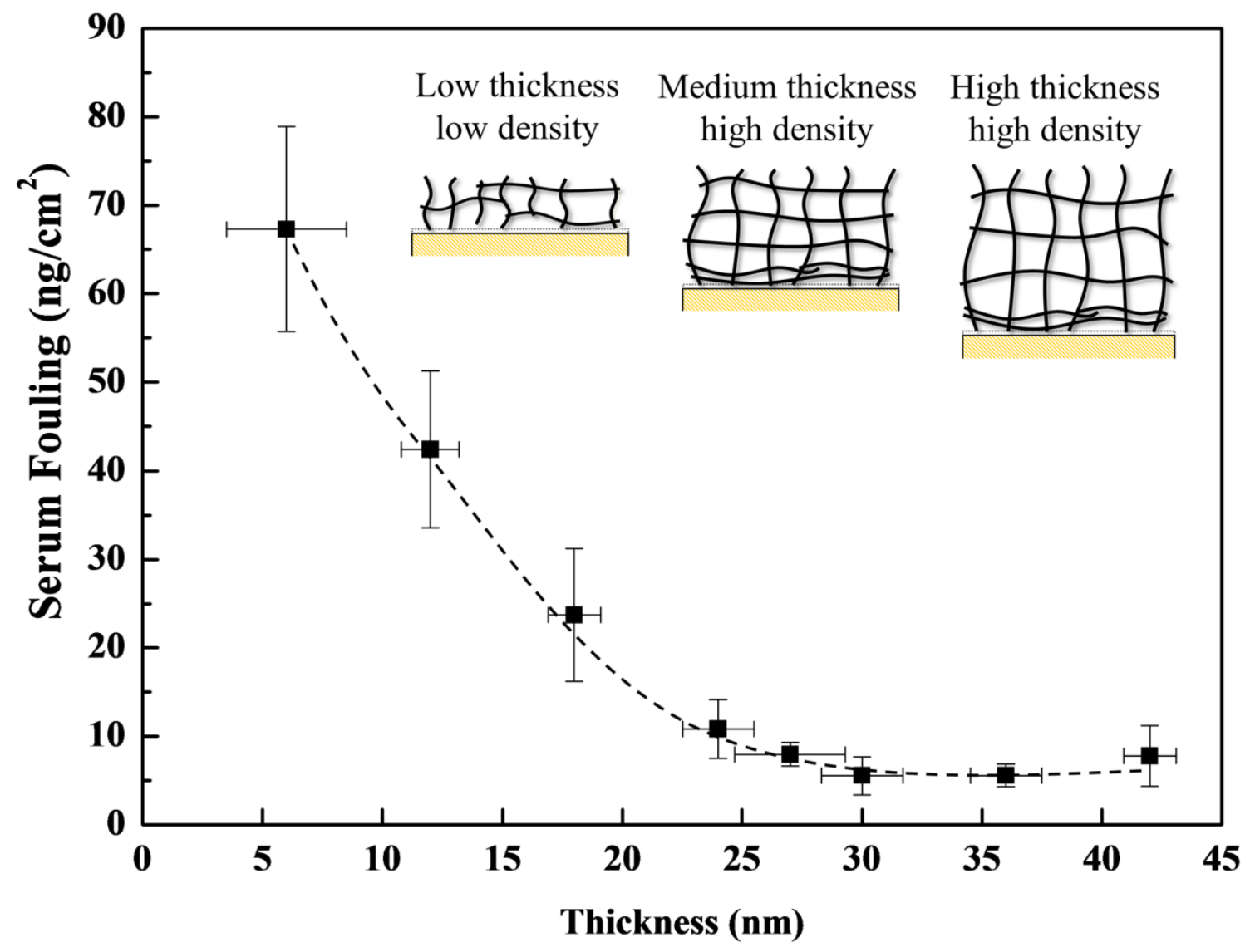

Fig 2. Protein adsorption on CBHTFs from $100 \%$ human blood serum measured by a SPR sensor as a function of film thickness. The error bars correspond to the standard deviation of three replicates. 


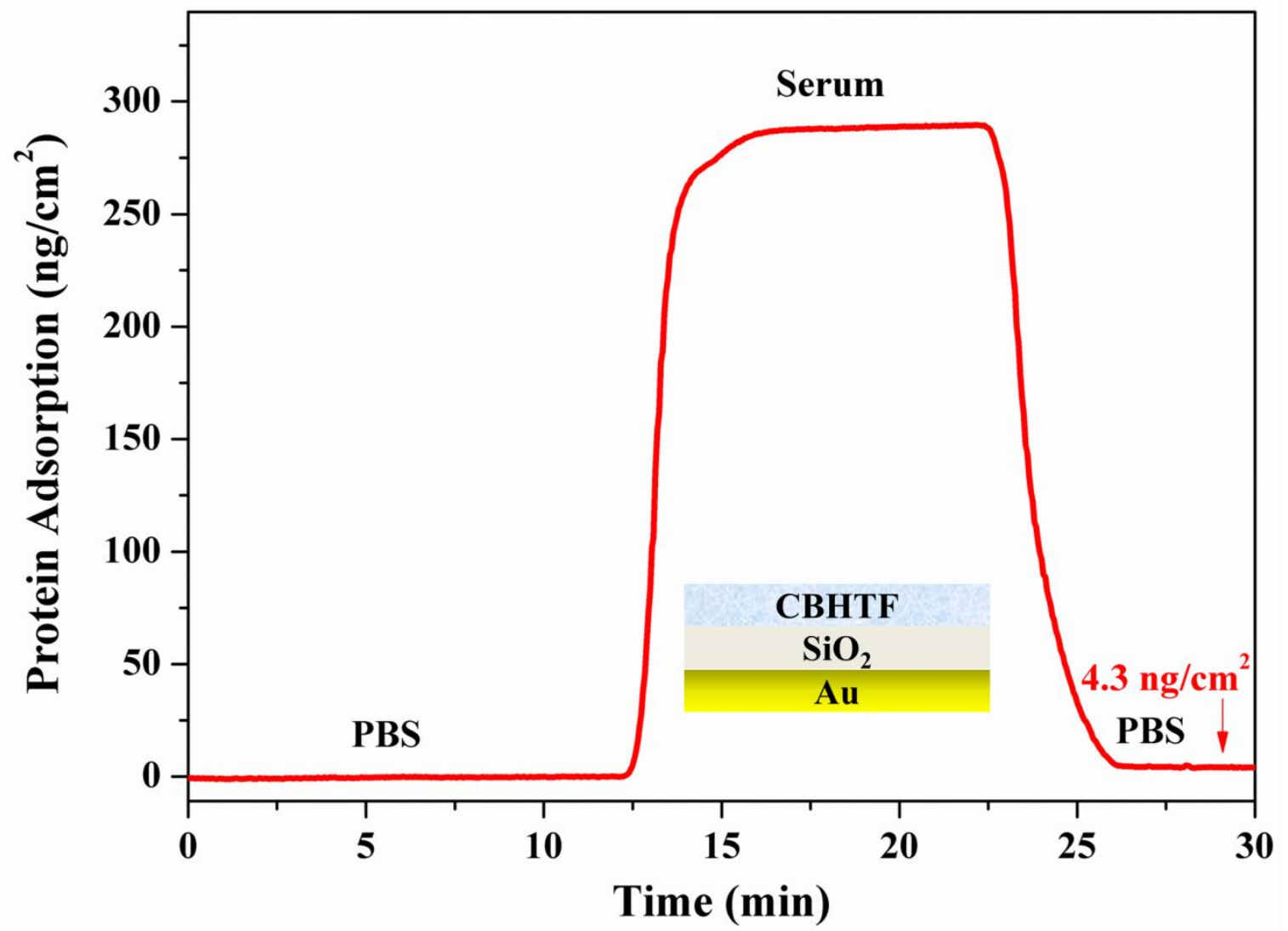

Fig 3. Typical SPR sensorgram for fouling tests on a CBHTF (thickness $=27.2 \mathrm{~nm}$ ) modified $\mathrm{SiO}_{2}$ surface in contact with undiluted human serum. 


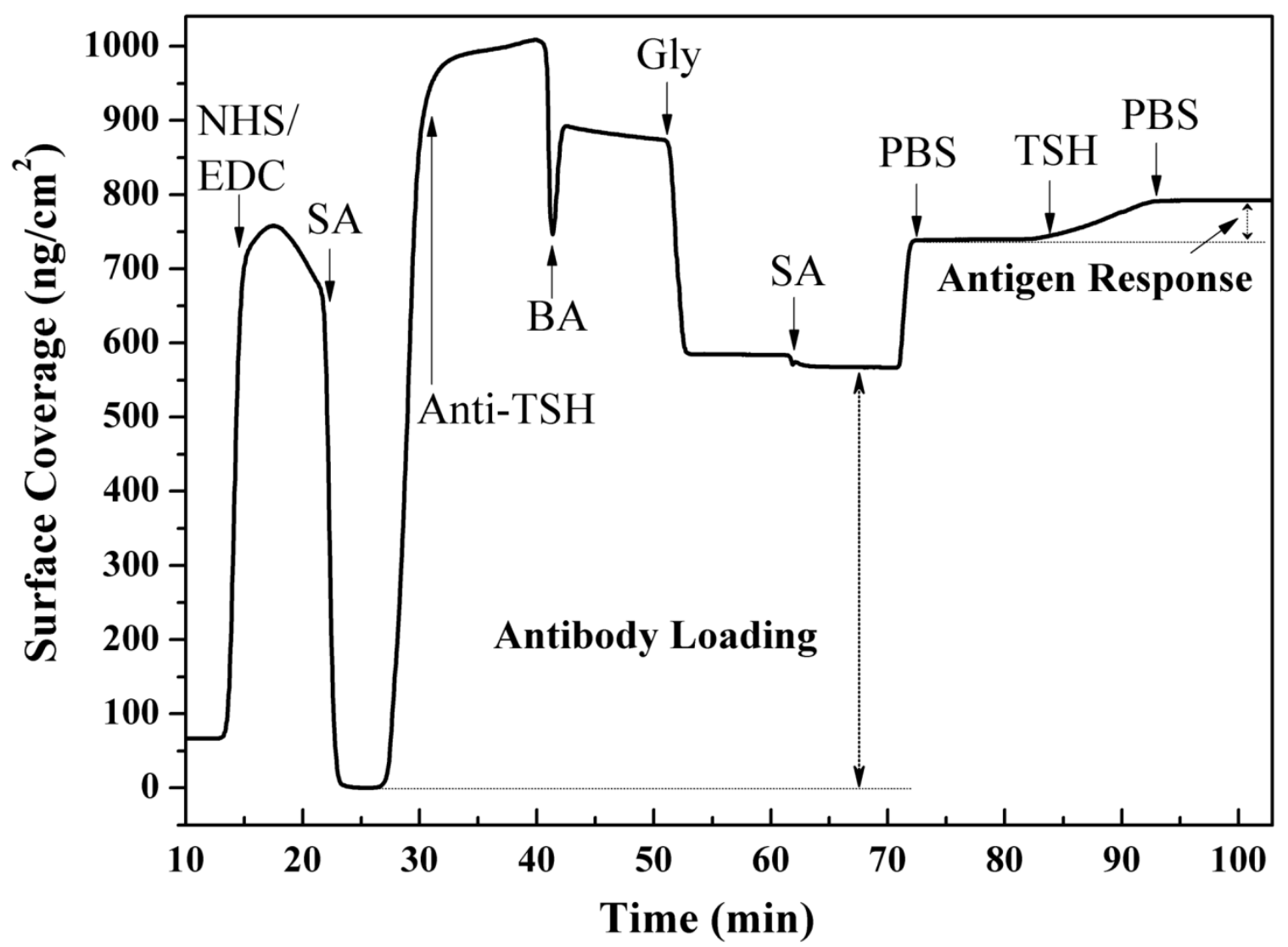

Fig 4. Typical SPR sensorgram for anti-TSH immobilization on CBHTF, followed by TSH antigen detection. 


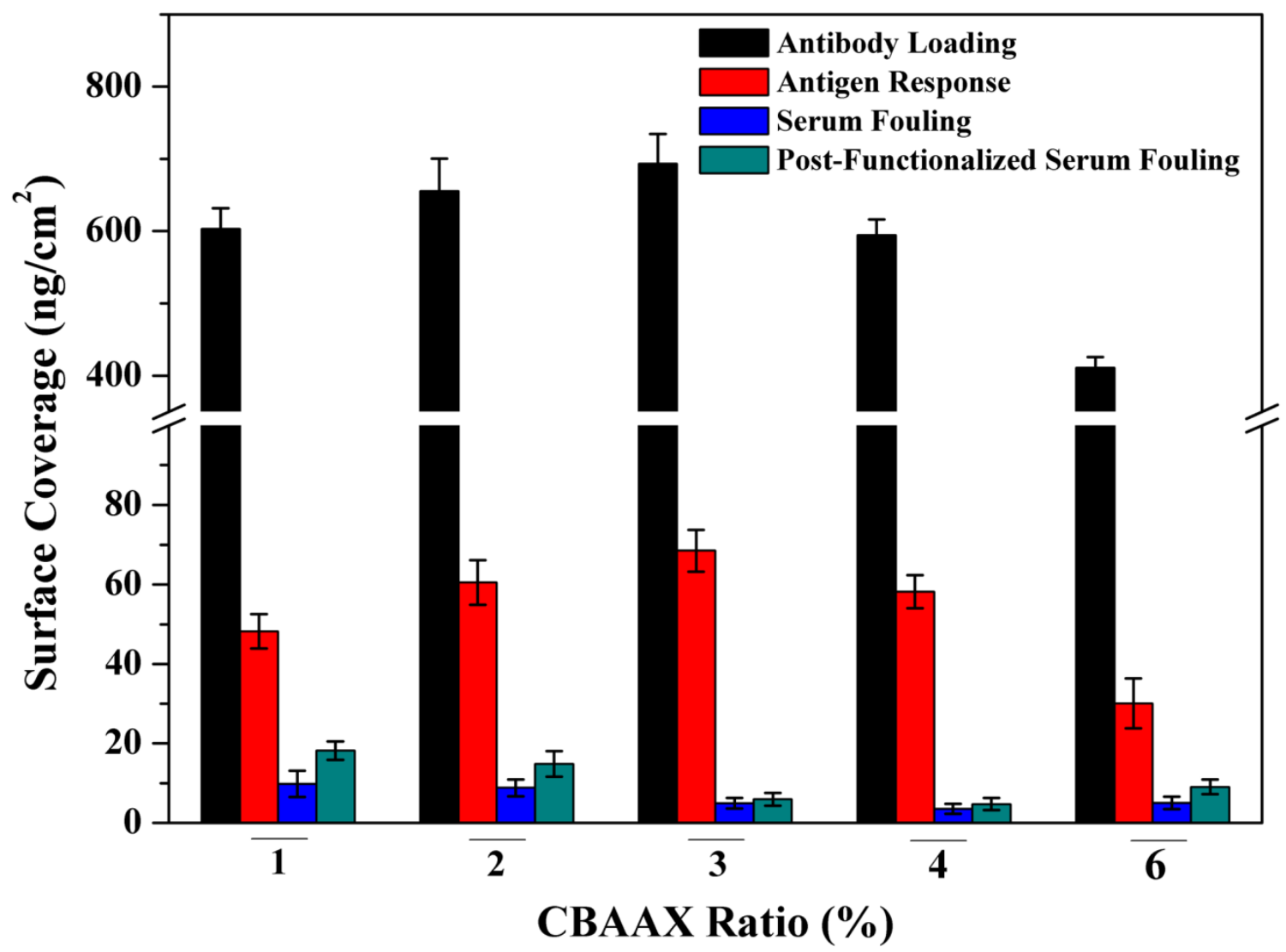

Fig 5. Antibody loading, antigen response, and nonfouling properties of CBHTFs as a function of CBAAX crosslinker ratio. The error bars correspond to the standard deviation of three replicates. 


\section{Graphical Abstract}

Ultra-low fouling zwitterionic

hydrogel thin film

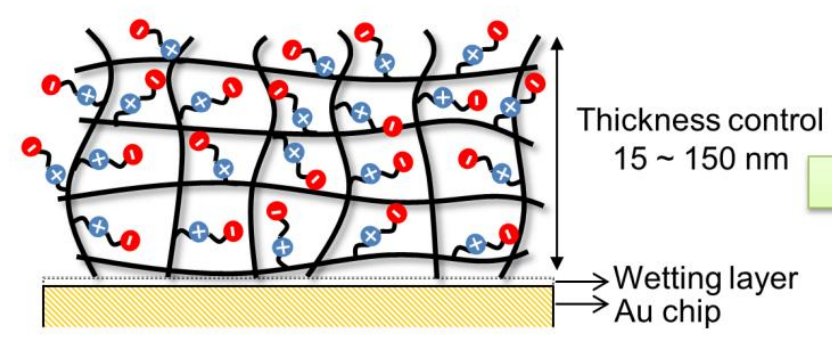

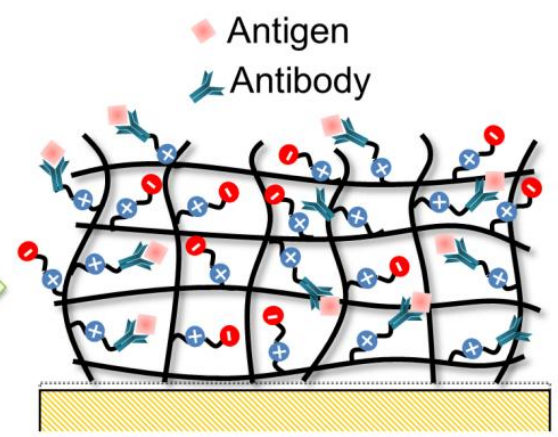

SPR biosensor 